\title{
CLÍNICA E ESTRATÉGIAS DE RESISTÊNCIA: PERSPECTIVAS PARA O TRABALHO DO PSICÓLOGO EM PRISÕES
}

\author{
Cristina Rauter \\ Universidade Federal Fluminense, Niterói, Brasil
}

RESUMO: Este trabalho é um estudo sobre a instituição prisional tomada como um dos componentes do dispositivo da criminalidade. Esse dispositivo de controle social é analisado como central no capitalismo contemporâneo, engendrando múltiplos efeitos mortificadores. Observa-se, no que diz respeito ao trabalho do psicólogo nas prisões, a decadência do discurso da recuperação e o fortalecimento de práticas coercitivas e punitivas. Por outro lado, o trabalho do psicólogo pode se inserir entre as estratégias de resistência e de vitalização.

PALAVRAS-CHAVE: Prisões; clínica transdisciplinar; subjetividade contemporânea.

\section{CLINICAL PSYCHOLOGY AND STRATEGIES OF RESISTANCE: PERSPECTIVES OF A PSYCHOLOGIST'S WORK IN PRISONS}

\begin{abstract}
This work is a study about penal institutions understood as a component of the "criminality device". The analysis of this social control device is carried out with the comprehension that it is a central aspect of contemporary capitalism, generating multiple lethal effects. Considering the work of psychologists in prisons, the decadence of the discourse of recuperation and the strengthening of coercive and punitive strategies was observed. On the other hand, a psychologist's work can be inserted between the strategies of resistance and vitalization.
\end{abstract}

KEYWORDS: Prisons; transdisciplinary clinics; contemporary subjectivity.

Todos os que vivem, têm parentes presos ou trabalham em prisões são atingidos cotidianamente pelos seus efeitos mortíferos. Pensamos as instituições carcerárias como componentes de uma grande engrenagem que designamos por "dispositivo da criminalidade". Não seria possível, como querem alguns, confinar os malfeitores num espaço à parte e deles se desobrigar, sem que essa prática produzisse efeitos sobre todo o campo social. Pensamos que as práticas que mantém as prisões em operação produzem envenenamentos subjetivos, no sentido espinosista do termo. (Deleuze, 2003). A solução prisional frente à questão da criminalidade só se torna possível porque põe em ação e se utiliza de múltiplos mecanismos subjetivos, para além das grades e muros. É nesse sentido que entendemos a proposta do criminólogo inglês Jock Young (2003), que considera que a solução penal e policial para a questão da criminalidade não é solução, mas sintoma. $\mathrm{O}$ dispositivo da criminalidade se constitui hoje numa das principais ferramentas de controle social no mundo globalitário. ${ }^{1} \mathrm{O}$ conceito de dispositivo, desenvolvido por Michel Foucault e explicitado por Gilles Deleuze (1990) permite por em relação diversos fenômenos que se processam no campo social de modo aparentemente dissociado. Dessa maneira, para pensar o fenômeno da criminalidade no contemporâneo, temos que considerar como parte de uma mesma engrenagem os discursos, as práticas, as instituições onde se operam essas práticas e esses discursos e os efeitos subjetivos que estes produzem no campo extra-institucional. Assim, consideramos como fazendo parte desse dispositivo o medo à criminalidade que se espalha nas cidades, as demandas punitivas produzidas através de discursos lei e ordem disseminados pela media, os efeitos subjetivos dessas campanhas, incluindo-se aqueles menos diretos, como a produção da apatia e o desânimo indo até o surgimento de múltiplas patologias que irão levar à utilização de medicação psiquiátrica, patologias somáticas, etc.

No interior da prisão processam-se complexos dispositivos subjetivos que irão como que "formar" aqueles que exercerão poder de mando e controle na instituição penal. Como se dá o estranho processo através do qual aqueles que provém do mesmo meio social, da mesma vizinhança, passam ocupar posições opostas, uns passando a ser a autoridade encarregada da custódia, da disciplina e outros encarnando o lugar da obediência, do erro, o lugar do "vagabundo", como costumam ser chamados os apenados pelos agentes penitenciários no Rio de Janeiro. Em especial na América Latina, onde a ilegitimidade do sistema penal (Zaffaroni, 1991) é tão flagrante face a extrema disparidade de renda entre as classes sociais, teremos que responder a pergunta de como se processam essas transformações subjetivas que acabam por opor de forma tão radical guardas e presos, por exemplo. Qual o ingrediente principal dessa transformação? A engrenagem carcerária, ao contrário das aparências, não trabalha apenas com a agressividade transformada em ressentimento e má consciência (Deleuze, 1978), no sentido nietzscheano, mas também com os sonhos daqueles que a reproduzem.

Como escapar do destino miserável daqueles que moram em guetos mas que observam de suas janelas televisivas a desejada e rica vida retratada nas novelas diárias? Há um meio, e esse meio passa por romper com essas relações 
de vizinhança que poderiam levar a laços de solidariedade. A libido que estaria sendo empregada na confecção desses laços de solidariedade, sendo impedida, passa a ter um sentido de anti-produção, de negatividade, transformandose em ódio. Também a produção do ressentimento faz parte desses processos: forças ativas que se tornam separadas do que elas podem, que se transformam em forças reativas. Encontrar um culpado! Tal é a solução, ao menos temporária. Encontrar o culpado em si próprio: a segunda etapa do adoecimento civilizatório, a má consciência descrita por Nietzsche. Os mecanismos em ação na prisão se utilizam com intensidade desse processos de produção do "bode expiatório". Tudo o que eu não tenho passa a ser culpa de alguém e esse alguém é concreto! É justamente aquele alguém que como eu nada tem e por isso rouba e até chega a matar. Ou que vive de vender drogas.

As ilegalidades populares são o principal alvo do dispositivo da criminalidade, composto pelas instituições penais e policiais, pelas campanhas lei e ordem, pelos complexos dispositivos de produção de estigmas, pela mídia, pela disseminação do medo, etc. O capitalismo quis conjurar justamente a possibilidade de que essas ilegalidades pudessem se alastrar e estabelecer parentescos indesejáveis, chegando mesmo a fazer com que a ordem capitalista não pudesse seguir conjugando o inconjugável: de um lado, uma extraordinária expansão dos meios de produção que dão à produção de bens materiais um caráter cada vez mais social e de outro, a manutenção de relações capitalistas de produção, de caráter privado. Esses processos não dizem respeito apenas ao interior da prisão. A prisão não se mantém apenas à custa da maldade dos agentes penitenciários e da polícia, ou mesmo do psicólogo, a face aparentemente mais branda de toda essa maquinaria mortífera. Processos de produção de subjetividade em ação em todo o campo social, através das instituições disciplinares já transformadas, na atual sociedade de controle, compõem essa formidável engrenagem, que tem como sub-produto a multiplicação do medo e da impotência, fruto justamente da transformação de parcelas imensas da energia libidinal em negatividade. Entre custodiadores e custodiados, todos estão imersos na problemática da criminalidade contemporânea, que deve ser vista na sua condição de sintoma do contemporâneo. Como um certo modo de experimentar a miséria de uma imensa maioria de deserdados desse sistema social globalitário, onde o desemprego não é circunstancial, mas inerente ao próprio sistema.

Na década de 70 Erving Goffman (1978/2005) referiu-se aos efeitos mortificadores da prisão, instituição total que se propõe a regular todos os aspectos da vida dos que a ela estão submetidos. Como demonstrou Foucault ao descrever as disciplinas, os lugares de poder no panoptismo são intercambiáveis, podem ser ocupados por diferentes atores institucionais, não se inscrevem mais na lógica bi- nária do tipo opressor/oprimido. Ora, sem o estabelecimento de tais redes horizontais, a maquinaria prisional não poderia se reproduzir. Não se pode supor um pequeno número de agentes penitenciários, cerca de vinte, pode controlar uma penitenciária com cerca de 800 homens sem o auxílio dessas redes horizontais de acordos e favores. Fazemos essas afirmações não no sentido de dizer que se trata de um abrandamento do poder, mas justamente, de um exercício de poder diante do qual não se pode estar a salvo, e por outro lado, que admite múltiplas estratégias de resistência.

Os psicólogos que atuam em prisões podem estar ameaçados caso não se proponham a reproduzir a engrenagem da instituição carcerária através de sua atuação. Por outro lado, estes profissionais estão colocados num lugar estratégico no sentido de produzir focos de resistência à rede de poder institucional. Mas para isso eles terão que se desprender de suas atribuições formais e formular outros modos de atuação direcionados no sentido oposto ao da mortificação institucional.

O que se observa no que diz respeito à atuação do psicólogo em prisões, é que ele está também prisioneiro de atribuições que muitas vezes vão no sentido contrário à ética profissional e à sua formação e mesmo "contra à lei" no sentido mais simples do termo. Apesar de uma alteração da Lei de Execuções Penais realizada em 2003 (Lei n. ${ }^{\circ} 10.792,2003$ ) ter tornado desnecessária a realização do exame criminológico para a concessão do Livramento Condicional e da progressão de regime, tal alteração não produziu qualquer modificação quanto à função e à freqüência com que são pedidos destes exames pelas autoridades da execução penal e do judiciário. Tal é o caso no Estado do Rio de Janeiro e também no Rio Grande do Sul, onde os psicólogos têm buscado organizar um movimento com apoio de seu conselho profissional denunciando essa situação.

Já me referi em artigos anteriores (Rauter, 2003) ao absurdo dessa situação, na qual o psicólogo (além de assistentes sociais e psiquiatras) é solicitado fazer previsões de comportamento através de laudos que instruem a concessão de benefícios e a progressão de regime, exercendo uma espécie de futurologia científica sem qualquer respaldo teórico sério. E isto, frequentemente a partir de um escasso conhecimento prévio do apenado, já que um número ínfimo de profissionais e um grande número de presos costuma inviabilizar que o profissional realize um acompanhamento individualizado do "paciente", reduzindo a feitura do laudo a mera função burocrática. $\mathrm{Ou}$ estariam sendo o psicólogo e os outros profissionais sendo convocados a exercer o dom da vidência?

A outra função para a qual é solicitado o Psicólogo lotado em unidades prisionais é a atuação em Comissões Técnicas de Classificação (CTCs) nas quais é decidida a 
aplicação de punições disciplinares, além de apreciadas solicitações de internos ao longo do cumprimento da pena. A CTC é uma espécie de reunião de equipe interdisciplinar da qual fazem parte agentes penitenciários e técnicos que trabalham numa unidade prisional. Ali são discutidas situações vividas no cárcere sob uma ótica predominantemente disciplinar. De um lado, o preso, posto no lugar de quem comete faltas, infrações, ou na melhor das hipóteses, faz solicitações e do outro, os agentes e técnicos, postos no lugar de quem julga, pune, absolve, concede etc. Ao psicólogo caberia, deste lugar, auxiliar na aplicação dessas medidas disciplinares, uma difícil missão cujos parâmetros ainda estão por ser definidos nos regulamentos oficiais.

Que função poderia caber ao Psicólogo a partir da Lei n. ${ }^{\circ} 10.792$ (2003)? Este instrumento legal, que é considerado por juristas progressistas um grande retrocesso nas leis penais brasileiras cria o Regime Disciplinar Diferenciado (RDD), que permite a manutenção de um apenado em situação de isolamento em período de até próximo de um ano. A mesma lei torna desnecessários os pareceres técnicos para instruir a concessão de livramento condicional e a progressão de regime. Estão reservados esses exames, doravante, apenas à individualização da pena. Realizados no início do seu cumprimento, eles orientariam a execução, no sentido de adequá-la às características pessoais do apenado. Alguns psicólogos entendem que, com o fim dos laudos, o psicólogo estaria destinado a uma tarefa terapêutica. Outros temem que fora da realização de laudos, tornem-se profissionais descartáveis para o sistema penal. De fato, ao menos no Rio de Janeiro, parece estar reservada preferencialmente à igreja evangélica essa tarefa de recuperação de almas nos cárceres, tal a quantidade de religiosos que hoje têm acesso aos presos, e por outro lado, a pequena quantidade de psicólogos em exercício nas unidades prisionais.

Mas que tarefa terapêutica seria essa à qual o psicólogo poderia se dedicar no interior da engrenagem carcerária?

Caso ele possa abster-se de fazer laudos (que como vimos, continuam ser solicitados apesar da nova lei ${ }^{2}$ ) abrese diante deste profissional todo um campo de trabalho que poderia ser da maior importância no sentido da construção de estratégias de resistência frente ao dispositivo da criminalização. O sistema penal vem se tornando destino de muitos jovens, preferencialmente os mais pobres, em nosso país. A população carcerária vem aumentando como decorrência da ação desse dispositivo em larga escala. Através das políticas "combate à drogas", setores das classes médias empobrecidos estão também chegando aos cárceres, condenados principalmente pelo tráfico de drogas. A criminalização do uso e da comercialização das drogas, realizada por um discurso belicista de inspiração norte-americana que tem norteado nossa legislação "antidrogas" desde a década de 70 (Carvalho, 2006), produz em larga escala o estigma do drogado e do traficante, que se generaliza por amplos setores da população jovem do país, que se torna como conseqüência "cliente" em potencial do sistema penal.

É esta complexa realidade com a qual se defronta o psicólogo que atua no sistema penal hoje. Caso possa escapar à prisionização da qual também é alvo, poderá se voltar para estratégias de resistência e não para a reprodução da engrenagem carcerária. $\mathrm{O}$ trabalho com grupos pode ser uma direção, como na experiência relatada pelo psicólogo Christian Fabiano Guimarães (2005). Numa instituição prisional do Rio Grande do Sul, os presos utilizavam o artigo pelo qual foram condenados como uma espécie de marca - escreviam-na nas paredes das celas, no próprio corpo... Embora se possa ver a tatuagem como estratégia de resistência na qual o corpo marcado serve para assinalar a criação de um território, o autor assinala que neste caso, a estratégia de resistência estava penetrada de ressentimento. Através dessa prática o apenado colava definitivamente um artigo do código penal ao seu corpo e à sua existência. Chamou à atenção do psicólogo a incapacidade de "colar" um outro adereço ao corpo. Por que não um outro nome? Porque selar definitivamente um destino de infrator do código penal? O que problematizamos aqui, a partir de uma clínica de resistência, é a impossibilidade de "colar" outros adereços ao corpo, construir outros projetos de vida.

Fenômenos como esse estão presentes também no trabalho de Aline Pereira Diniz (1988). Nas assim denominadas "assembléias" realizadas a cada manhã, num CRIAM, com a participação da equipe e dos jovens que ali cumprem medidas sócio-educativas, o assunto principal era o relato, feito pelos próprios jovens, de furtos realizados por colegas e o pedido de punições duras, freqüentemente mais duras do que as que seriam impostas pelos profissionais do estabelecimento. Como se os jovens dissessem ironicamente à equipe: vocês nos consideram bandidos, então... é isso que somos! Ou; nós mesmos queremos a punição! $\mathrm{O}$ estigma do infrator parecia girar como no jogo do mico preto, entre os adolescentes participantes da reunião. Ao saírem para passeios longamente esperados, costumavam também furtar. Exibiam orgulhosamente o pertencimento às facções do tráfico de drogas. Tal pertencimento era muitas vezes gritado em tom entre orgulhoso e ameaçador. Novamente aqui a repetição estereotipada de estigmas revela uma incapacidade de "fazer diferente" que atinge tanto os técnicos e os jovens clientes do CRIAM. Tal impossibilidade diz respeito ao funcionamento da engrenagem carcerária e a seus efeitos.

Francisco Gaspar Neto, em suas experimentações com teatro realizadas numa instituição voltada para o tratamento de jovens usuários de drogas em São Gonçalo, o CRIAA-UFF, lida com as marcas produzidas tanto pelas instituições penais e policias quanto pelo tráfico de drogas. 
Um corpo enrijecido é um dos aspectos da produção do estigma do criminoso e do drogado.
... o efeito do exercício [exercício de guiar o cego] foi sentido particularmente sobre um dos adoles- centes; ele trabalhara no tráfico desde os dez anos e já tinha passado por várias instituições penais; ele era um dos que mais enunciava a lógica prisional, dizendo que homem não tomava banho, etc. Quando ele teve que tocar o rosto de outro companheiro era possivel perceber que suas mãos estavam trêmulas e hesitantes... quando foi pedido que todos ... se olhassem, esse adolescente deu um pulo para trás, correu para o outro canto da sala e ficou olhando o grupo com olhar assustado... o corpo do adolescente foi afetado, mas por forças estranhas, não mais aque- las que redundavam no território do já conhecido, forças que aprisionam, que obrigam a repetição do hábito, que suscitam sempre a mesma resposta cor- poral (Gaspar Neto, 2005, p. 107).

Pertencer é uma justa reivindicação adolescente. Mais do que uma reivindicação, é um poderoso impulso que o despertar da sexualidade adolescente traz consigo. O poder agregador de Eros! Sabemos o quanto a massificação, o pertencimento modelizante pode afetar também a subjetividade do adolescente. A propaganda consumista também se aproveita criminosamente desse seu anelo por pertencimento. Para exercer essa clínica de resistência no interior da engrenagem carcerária o psicólogo terá que tirar o seu avental branco (Guattari, 1990, p. 20), deixar Édipo no cabide, as famosas famílias desestruturadas e também certas concepções sobre a pulsão de morte, que propõem que uma irresistível tendência para o mal esteja no coração do psiquismo humano necessitando ser limitada ou coibida. A construção de estratégias de resistência frente à mortificação passará frequientemente pela arte, pelo trabalho com grupos, ou por estratégias de atendimento individual que possam intensificar os processos vitais. Não para apontar a salvação, a expiação de culpas, para se substituir o julgamento externo por um auto-julgamento, ou para propor a vida eterna como compensação para os sofrimentos desse mundo... Seria necessário, para aquele que se propõe a essa tarefa de tratamento, colocar o delito entre parênteses, porque uma vez julgado e condenado, o detento começa a "pagar" sua dívida com a sociedade, como se diz no jargão carcerário. $\mathrm{O}$ tratamento não pode ser uma nova situação de julgamento.

Há uma certa monotonia reinante também no campo das psicoterapias (Rauter, 2005). Temos que ser capazes de propor algo além de "dar limites" ou de fazer diagnósticos de enfraquecimento da lei paterna, passando por uma compreensão do crime a partir de um interior (pulsão de morte, etc.) se quisermos construir estratégias de resistência à prisionização, tanto do psicólogo quanto dos que têm como o destino as nossas prisões. Alguns referenciais teóricos levam a que o psicólogo acabe não tendo nada de muito diferente a propor neste campo, tornando-o cúmplice de estratégias repressivas, mortíferas, de justificação do encarceramento. Sabemos que o estigma do criminoso é produzido pelo próprio dispositivo da criminalização em seus múltiplos componentes e não a partir do cometimento pura e simples de atos criminosos.

A denúncia das péssimas condições carcerárias é também tarefa do psicólogo e para que possa realizá-la, deve construir redes, rompendo o isolamento da prisão. Nessa denúncia ele também se utiliza de seus conhecimentos teóricos, pesquisando e teorizando sobre os efeitos do isolamento, de práticas como o RDD, da inatividade física e mental, numa perspectiva em que clínica e política são indissociáveis. Não tivemos ainda no Brasil um movimento no campo penal semelhante ao da "reforma psiquiátrica", que conseguiu a aprovação de uma lei que aponta para a extinção progressiva dos manicômios. As nossas prisões e instituições "sócio- educativas" exibem uma face cruel. Um recente relatório elaborado pelo Conselho Federal de Psicologia sobre essas instituições destinadas a crianças e adolescentes, mostrou numa delas a inexistência de banheiros (no estado do Sergipe), noutra, o uso excessivo de medicação psiquiátrica. (no Rio Grande do Sul). Na maioria delas jovens são mantidos ociosos, a higiene é precária. Em muitas, castigos físicos são utilizados (Ordem dos Advogados do Brasil [OAB], Conselho Federal de Psicologia [CFP] \& Comissões de Direitos Humanos dos Conselhos Regionais de Psicologia, 2006).

O contexto atual da execução penal está caracterizado pela decadência do discurso da recuperação. Se até a década de noventa esse discurso podia ser denunciado como falso, hoje o que percebemos é o fenômeno de sua rarefação. Há um clamor pela punição, pelo encarceramento, que se dissemina por amplos setores da população, chegando a justificar a tortura e o extermínio de bandidos. Uma lógica do bem e do mal perpassa os meios de comunicação e se impõe de forma globalizada. Consideramos que a questão da criminalidade ganha hoje um lugar central na produção de subjetividade no contexto do capitalismo globalizado atual. A difusão de lógicas binárias que opõem cidadãos honestos que merecem viver a terroristas e bandidos vai desde Guantânamo, passando pela Europa e o Japão e chegando até o Brasil, com a adoção do RDD, acrescentando-se à prática semi-oficial do extermínio pela polícia à céu aberto, como verificamos nos acontecimentos que se seguiram aos denominados "ataques" atribuídos a organizações criminosas em São Paulo.

Que papel estaria reservado aos psicólogos nos cárceres nesse contexto de rarefação do discurso da recuperação? Um dos panoramas que podemos visualizar é até mesmo o de um "fortalecimento" dos laudos psicológicos com a função de estabelecer uma triagem. É nessa direção que 
a aponta a tese da psiquisatra Hilda Morana (2003), ao validar para a "população forense" brasileira a Escala HarePCR, que permite diagnosticar a psicopatia, separando assim "o joio do trigo". Através da simples aplicação de um questionário, o técnico treinado poderá produzir pareceres mais fundamentados para concessão de benefícios e para a inclusão ou não de determinado apenado num programa re-socializador.

A atual administração da secretaria da administração penitenciária tem por critério a separação dos condenados por tipo de delito... é neste projeto que o trabalho tem relevância, pois permite, com a aplicação do PCL-R, separar os psicopatas do convívio com os criminosos comuns (Morana, 2003, p. 154).

O trabalho dessa pesquisa já tem firmado com o senhor secretário da administração penitenciária uma proposta ulterior de uma vez treinadas equipes para aplicação do PCL-R, já traduzido e validado para a população brasileira, identificar os psicopatas na população carcerária e remove-los para ambiente penitenciário adequado. Esta proposição tem o objetivo de liberar as prisões da influência nefasta dos mesmos e dessa forma promover a reabilitação dos criminosos não psicopatas, a exemplo de países como Canadá e Inglaterra... (Morana, 2003, p. 39).

Para Morana (2003) há prisioneiros que não devem entrar em programas de recuperação porque são psicopatas, acometidos do que ela prefere denominar "transtorno global" de personalidade (a autora prefere esse diagnóstico ao de Transtorno Anti-Social e desenvolve na tese algumas razões, que não cabe aqui apresentar). São incuráveis e devem apenas cumprir penas de prisão. A autora apresenta às autoridades carcerárias um instrumento econômico e objetivo, capaz de medir se o apenado é psicopata e em que grau. Na tese aprendemos também que, submetido a tratamento psicoterápico não importa com qual abordagem, os portadores do Transtorno Global de Personalidade, não só não melhoram como chegam a piorar! E são apresentadas algumas possíveis causas etiológicas para o transtorno, que vão desde as genéticas até as relacionadas ao abuso sexual na infância, enfatizando-se sempre a incurabilidade.

O “instrumento" consiste na aplicação de um questionário que versa, de um modo geral, sobre sinais de litígio com as normas e leis num histórico que começa desde a infância, passando pela capacidade de estabelecer vínculos afetivos que vão do familiar (separações) ao escolar (abandono escolar), vínculos com trabalho, à promiscuidade sexual, ao uso de drogas. Enfatiza-se a frieza afetiva e a versatilidade no cometimento de crimes, já que a psicopatia não está relacionada a um delito especial, mas a uma tendência geral ao cometimento de delitos.
Nesse contexto, creio eu, será necessário muitas vezes empunhar a bandeira do tratamento e da recuperação como estratégia para colocar obstáculos ao extermínio subjetivo que se anuncia no momento atual como técnica de execução penal. A monotonia cinzenta dos presídios de "segurança máxima", que leva muitos ao enlouquecimento e à morte: talvez seja esse o tipo de estabelecimento considerado adequado para o cumprimento da pena quando se trata de psicopatas. E as prisões estão mesmo cheia deles, segundo estatísticas que constam desse e de outros estudos psiquiátricos atuais, realizados na perspectiva da atual psiquiatria biológica! As prisões brasileiras têm sido comparadas por organismos internacionais com campos de concentração, em muitos casos em versão piorada àqueles construídos pelos nazistas, ao menos no que diz respeito ao espaço físico. Muitos profissionais acostumados a lidar em todo o mundo com realidades extremas como campos de refugiados e prisões, confessam nunca terem visto algo semelhante à extinta prisão da Polinter no Rio de Janeiro, que foi mostrada no brilhante Documentário de José Padilha "Ônibus 174", em 2002. A bandeira do tratamento e da recuperação, se empunhada pelos técnicos que atuam nos cárceres, pode ser uma estratégia de resistência política à mortificação generalizada presente neste campo. Que é também a mortificação dos próprios profissionais, caso estes não consigam articular saídas viáveis para sua atuação. A palavra tratamento é aqui usada estrategicamente: construção de estratégias vitais diante de um horizonte de extermínio. Mas os psicólogos não estariaminventando sozinhos essas estratégias: elas já estão presentes no campo social e no interior das próprias prisões, cabendo-lhes o papel de catalisador. Como a organização do poder não segue uma lógica binária, situações complexas deverão ser analisadas. Não necessariamente dos presos estarão partindo estratégias de vida pois nem mesmo eles detêm a verdade sobre a instituição carcerária, no sentido de que não são "a voz do oprimido" ou novamente estaríamos caindo num outro tipo de dicotomia. Outra concepção que deverá ser deixada "no cabide" é a oposição binária opressor/oprimido (Gaspar Neto, 2005, p. 116), se queremos compreender e intervir sobre o que aqui denominamos "dispositivo da criminalização".

\section{Notas}

Preferimos o termo "globalitário" cunhado pelo geógrafo Milton Santos já que permite destacar que não se trata de condenar os processos de globalização em curso no capitalismo atual, mas um certo tipo de globalização, que condena à miséria e à morte uma significativa parcela da população no mundo atual. Por outro lado, é o fenômeno da globalização que possibilita que hoje possamos alimentar toda a população da terra com os meios tecnológicos de que dispomos (Santos, 2001).

2 No Rio Grande do Sul uma portaria da Secretaria de Justiça reedita a necessidade de realização do exame criminológico em flagrante contradição com a lei federal. 


\section{Referências}

Carvalho, S. (2006). A política criminal de drogas no Brasil: Estudo criminológico e dogmático (3. ed.). Rio de Janeiro, RJ: Lúmen Júris.

Ordem dos Advogados do Brasil, Conselho Federal de Psicologia, \& Comissões de Direitos Humanos dos Conselhos Regionais de Psicologia. (2006). Uma amostra das unidades de internação de adolescentes em conflito com a lei: Inspeção nacional às unidades de internação de adolescentes em conflito com a lei. Brasília, DF: OAB.

Deleuze, G. (1978). Nietzsche e a Filosofia. Rio de Janeiro, RJ: Rio.

Deleuze, G. (1990). O que é um dispositivo? In L. Janeira (Ed.), L. Michel Foucault, filósofo (pp. 155-161). Barcelona, España: Gedisa.

Deleuze, G. (2003). Espinosa e a filosofia prática. São Paulo, SP: Escuta.

Diniz, A. P. (1988). A lógica criminológica e a atuação do psicólogo junto ao adolescente envolvido com a prática de ato infracional. Monografia de Especialização não-publicada, Departamento de Psicologia, Universidade Federal Fluminense, Niterói, RJ.

Gaspar, F., Neto. (2005). As experiências teatrais e intervenções clínicas: Pressupostos teatrais nas oficinas terapêuticas. Dissertação de Mestrado não-publicada, Departamento de Psicologia, Universidade Federal Fluminense, Niterói, RJ.

Guattari, F.(1990). As três ecologias. Campinas, SP: Papirus.

Goffman, E. (2005). Manicômios, prisões e conventos (7. ed.). São Paulo, SP: Perspectiva. (Original publicado em 1978)

Guimarães, C. F. (2005). Subjetividade e estratégias de resistência à prisão. Dissertação de Mestrado não-publicada, Universidade do Vale do Rio dos Sinos, São Leopoldo, RS.

Lei n. ${ }^{\circ}$ 10.792. (2003). Altera a Lei de Execuções Penais no que diz respeito aos requisitos para obtenção de Livramento Condicional e outros benefícios e cria o Regime Disciplinar Diferenciado. Brasília, DF.
Morana, H. (2003). Identificação do ponto de corte PCJ-R (Psychopaty Checklist Revised) em população forense brasileira. Caracterização de dois subtipos de personalidade: Transtorno global e parcial. Tese de Doutorado não-publicada, Faculdade de Medicina, Universidade de São Paulo, SP.

Rauter, C. (2003). Criminologia e subjetividade no Brasil. Rio de Janeiro, RJ: Revan.

Rauter, C. (2005). Para além dos limites. In R. Néri \& M. Menegat (Eds.), Criminologia e subjetividade (pp. 47-54). Rio de Janeiro, RJ: Lúmen Júris.

Santos, M. (2001, dez.). Contra o globalitarismo. Entrevista concedida a Raquel Aguiar. Revista Ciência Hoje On line, Rio de Janeiro. Retirado de http://cienciahoje.uol.com.br/.

Young, J. (2003). A sociedade excludente. Rio de Janeiro, RJ: Revan.

Zaffaroni, E. R. (1991). Em busca das penas perdidas: A perda de legitimidade do sistema penal. Rio de Janeiro, RJ: Revan.

Cristina Rauter é Professora do Departamento de Psicologia da Universidade Federal Fluminense. Endereço para correspondência: Rua Major Fróes, 225, São Francisco, Niterói, RJ, 2436-5030. rauter@terra.com.br

\section{Clínica e estratégias de resistência: perspectivas} para o trabalho do psicólogo em prisões

Cristina Rauter

Recebido: 06/12/2006

$1^{a}$ revisão: 19/03/2007

Aceite final: 08/05/2007 